\title{
Impact of SMEs in economic growth in Albania
}

\author{
Grisejda Myslimi ${ }^{1}$, Krisdela, Kaçani ${ }^{1}$
}

\begin{abstract}
SMEs are main indicators of a country's economic development. They have a significant impact on the social development of a country. SMEs create jobs, compete with big enterprises, become part of the global market, contribute to poverty alleviation in developing countries, boost exports and reduce imports.

An important objective of this study is to analyze the impact of SMEs on economic growth in Albania during the period of 1995-2015. To achieve this objective, it will be evaluated empirically the impact of SMEs on the economic growth in Albania through the use of statistical programs. It will be interpreted the casual links between SMEs and economic growth. Economic growth is determined by Gross Domestic Product at current prices (real GDP). The result achieved empirically, will be also proved thanks to the various diagnostic tests.

Based on the empirical results it is evident that in the economic growth of Albania, affect major and micro enterprises. This result can be explained by the fact that large enterprises are more competitive than SMEs. They can withstand economic crises easier than SMEs, through the use of the economies of scale.
\end{abstract}

Key words: SMEs, Economic growth, Real GDP, Size of the Enterprises

\section{Introduction}

SMEs play an important role in promoting economic development. (ACS 1997) comes to the conclusion that small firms are the engine of global economic growth. In most countries, SMEs dominate the industrial and commercial infrastructure (Deros 2006). Economists believe that the wealth of nations depends on the performance of their SMEs (Schröder, 2006). In developed countries and developing countries, SMEs contribute to the stability of the national economy. They help the economy cope with the shocks of economic cycles. SMEs serve as the main engine for the equal distribution of income among workers (Choi, 2003). SMEs managers should invest less in tangible assets, but more in R \& D (Gassmann dhe Keupp, 2007).

\subsection{The concept of SMEs}

There is not a static definition for SMEs (Altman, Sabato and Wilson, 2008; Henschel, 2009). This is because there are no uniform criteria to measure them in terms of their amount of capital, number of employees, turnover, investment in fixed capital and machinery, and market share (Ogechukwu, 2011). These differences between SMEs are observed from country to country, from industry to industry,and from author to authors (Fatai 2010).

In order to minimize the controversy generated by differences in the classification of SMEs, many authors define SMEs under two categories (Altman 2008; Henschel 2009). 
These are theoretical and operational definitions. Henschel (2009) specifically states that theoretical definitions of SMEs considers qualitative criteria such as autonomy, personal understanding as well as financial and personal commitment of the owner. The author further states that an operational definition of SMEs takes into account quantitative criteria such as the annual turnover, number of employees and capital expenditures.

According to UNEP (2003), The European Union argues that micro firms are those which employ fewer than 10 employees and an annual turnover of around 2 million euros, small firms employing less than 50 employees and about 10 million euros of annual turnover, while the medium sized firms employ less than 250 employees with an annual turnover of 43 million euros.

\subsection{The hypothesis of study}

$\mathrm{H}_{0}$ : There exist not a statistically significant link between SMEs and economic growth in Albania.

$\mathrm{H}_{a}$ : There exist a statistically significant link between SMEs and economic growth in Albania.

\subsection{Research Objectives}

- $\quad$ To assess empirically the influence of SMEs in the economic growth of Albania. Analyze the impact of SMEs on the economic growth through statistical programs.

- To analyze or interpret causal links between SMEs and economic growth. So, to estimate why do SMEs affect or do not affect the economic growth in our country

\subsection{The research question}

- Do SMEs have an impact on the economic growth of Albania?

\subsection{Scope of the study}

The study has used the annual data for a period of 20 years. The data belong to the time period of 1995-2015. It has been studied the impact of enterprises of any size in the economic growth in Albania, in order to understand which size of enterprises affect more the economic growth in the country. Economic growth is determined by Gross Domestic Production at current prices (real GDP). So through the study it will be analyzed the effect of micro enterprises, small enterprises, medium enterprises and large enterprises in the GDP.

\section{The relationship between SMEs and economic growth}

Recently the role of SMEs in the economic development has been one of the most important discussion between the government, policy makers, academics, researchers, scholars and economists. SMEs:

o create new jobs

o expand the tax base

o contribute in innovation 
0

enhance competition

0 increase the aggregate productivity etc.

SMEs provide to the economy with ongoing ideas, skills and innovation (CACCI, 2003). They dominate the world economy in terms of employment. Given that SMEs enhance competition, promote efficiency, innovation and productivity, the government support of SMEs can help countries reap the social benefits. The SMEs subsidy can help to reduce poverty. But it could not be diminished the value that large enterprises have in the economic growth.

\subsection{The impact of SMEs in the national income / GDP}

Through the creation of employment the disposable incomes will rise further, contributing to the increase of the social standards. Consumption will also increase, impacting positively on the national incomes (Keskin, Dhe Senturk 2010). This is proved by the equation of the national incomes:

$$
(\mathrm{Y}=\mathrm{C}+\mathrm{I}+\mathrm{G}+\mathrm{X}-\mathrm{M})
$$

Therefore, the employment growth leads to the development of innovation and increasing the production. The business expands contributing in the reduction of imports and increasing the exports and domestic production. The business expansion leads to increased investment. Employment growth leads to increased social standards. The consumption increases, contributing to the growth of national income.

There are many success stories in the world where the adoption of an appropriate strategy for the establishment and promotion of SMEs has given impressive results in the economic growth (Steensma, Marino dhe Weaver 2000). Lefebvre dhe Elisabeth (2001) have shown the impact of the innovative capabilities of SMEs as the main determinant on export performance. All the technological capabilities of SMEs are significantly positively correlated with exports.

The data show that SMEs are vital to the economic health, worldwide, in countries with high income economies and low-income, SMEs are adversely affected by the global financial crisis of the year 2008. The contribution of SMEs in GDP is important. SMEs account for $52 \%$ of the value added in the private sector, which is a reasonable estimate for the global economic contribution (ACCA 2010).

Statistics rarely deny the influence of SMEs in GDP. For example, in 2006/7, the contribution of SMEs to the GDP of India was only around $6 \%$. Thus, the output of SMEs accounted for about $40 \%$ of the industrial production and $40 \%$ of all exports (Ghatak 2010).

\subsection{The impact of SMEs on employment}

SMEs are the main actors of innovation and competitiveness. Empirical studies show that SMEs play an important role in generating employment, innovation, economic growth and unemployment reduction (Garikai, 2011). The great advantage of SMEs is the employment potential with low cost capital. SMEs with more intensive work impact more the employment (Wymenga, 2011). SMEs with greater workload intensity create more jobs, having lower capital costs than large firms (Liedholm and Mead 1987; Schmitz 1995). This is especially important for developing countries and economies with 
high unemployment rate.

SMEs in the European Union are seen as essential for the European employment. SMEs account for $65 \%$ of business turnover in the European Union and provide around 90 million jobs. According to Muragia (2008) entrepreneurs of SMEs in America are known for their role in the creation of new jobs, in providing competition to existing businesses, improve product quality, in offering lower prices, and the introduction of goods and new services through innovation and the advancement of technology.

\section{The correlation between SMEs and GDP in Albania}

Through this study it is aimed to analyze whether SMEs in Albania affect the economic growth. Are studied the data which belong to the period $1995-2015$. In consideration are taken five variables from which the dependent variable is GDP (gross domestic production at current prices). Data are obtained on an annual basis. It will be examined the impact that each enterprise size has on the economic growth. At the end we will conclude whether economic growth in Albania is linked to SMEs or large enterprises.

\section{Variables taken in the study are:}

Y - dependent variable - real GDP

$\mathbf{X}_{1}$ - independent variable - nr. of micro enterprises

$\mathbf{X} 2$ - independent variable - nr. of small enterprises

$\mathbf{X}_{3}$ - independent variable - nr. of medium enterprises

$\mathbf{X}_{4}$ - independent variable - nr. of large enterprises

Once the data are added and processed in EVIEWS, the below output is taken:

Dependent Variable: Y

Method: Least Squares

Date: 06/19/15 Time: 11:29

Sample: 19952014

Included observations: 20

\begin{tabular}{lllll}
\hline \hline Variable & Coefficient & Std. Error & t-Statistic & Prob. \\
\hline \hline C & 273406.6 & 70303.14 & 3.888968 & 0.0015 \\
X1 & 10.37378 & 3.110808 & 3.334755 & 0.0045 \\
X2 & -121.2405 & 95.26647 & -1.272646 & 0.2225 \\
X3 & -27.17384 & 142.2630 & -0.191011 & 0.8511 \\
X4 & 632.8496 & 395.6210 & 1.599636 & 0.0035 \\
\hline \hline R-squared & 0.983794 & Mean dependent var & 829683.6 \\
Adjusted R-squared & 0.979473 & S.D. dependent var & 372560.4 \\
S.E. of regression & 53377.81 & Akaike info criterion & 24.82050 \\
Sum squared resid & $4.27 \mathrm{E}+10$ & Schwarz criterion & 25.06943 \\
Log likelihood & -243.2050 & Hannan-Quinn criter. & 24.86909 \\
F-statistic & 227.6511 & Durbin-Watson stat & 0.567584 \\
Prob(F-statistic) & 0.000000 & & \\
\hline \hline
\end{tabular}

Source: Author's computation, 2016 


\section{Interpretation of the model}

Based on the studied model, we have the following equation:

$\mathrm{Y}=273406.6+10.37378 \times 1-121.2405 \times 2-27.17384 \times 3+632.8496 \times 4$

Prob.(F-statistic) $=0<0.05$, the alternative hypothesis is accepted, which means that there is at least one variable $\mathrm{X}$ that affects $\mathrm{Y}$.

Testing of importance/existence of parameters:

Parameter $\mathrm{C}$ (the constant) exists

Parameter $\beta 1$ exists because Prob. $<0.05$

Parameter $\beta 2$ does not exists because Prob. $>0.05$

Parameter $\beta 3$ does not exists because Prob. $>0.05$

Parameter $\beta 4$ exists because Prob. $<0.05$

Measurement of the variation:

The coefficient of determination / Adjusted R2 :

$\checkmark \quad$ The proportion on the variation of $\mathrm{Y}$ that "is explained" by all the $\mathrm{X}$ variables taken together.

$\checkmark \quad \mathrm{R}^{2}$ adjusted $=0.9794$

$\checkmark \quad 97,94 \%$ of $\mathrm{Y}$ variations are explained by $\mathrm{X}$ variation

The econometric equation model, is: $\mathrm{Y}=\mathrm{C}+\beta_{1} \mathrm{X}_{1}+\beta_{4} \mathrm{X}_{4}$

$$
Y=273406.6+10.37378 X_{1}+632.8496 X_{4}
$$

In conclusion we can say that the the enterprises that affect the economic growth in Albania are not SMEs, but large enterprises. The alternative hypothesis is rejected and the null hypothesis accepted. SMEs in their entirety do not affect the economic growth. Economic growth in Albania is influenced only by the micro enterprises (which are part of SMEs), and large enterprises. Large enterprises have a greater impact on the economic growth than micro enterprises.

\subsection{Diagnostic tests and adaptability of the model}

These tests aim to test and certify all the initial assumptions of the model.

\section{Testing of homosedasticity}

a) $\mathbf{A R C H}$ test: is an autoregression procedure above the square of wastes over time: $\mathbf{\varepsilon} \mathbf{2 t}=\varphi \mathbf{1} \mathbf{\varepsilon} \mathbf{t}$ $1+\varphi 2 \varepsilon 2 \mathrm{t}-2+\ldots \ldots .+\varphi \varrho \varepsilon 2 \mathrm{t}-\varrho+\eta \mathrm{t}$

Hypotheses:

$\rightarrow \quad \mathrm{H} 0: \varphi 1=\varphi 2 \ldots \ldots=\varphi \varrho=0$ Homosedasticity

$\rightarrow \quad$ Ha: Të paktën një koefiçent $\neq 0:$ Heterosedasticity

Heteroskedasticity Test: ARCH

\begin{tabular}{llll}
\hline \hline F-statistic & 0.108400 & Prob. F(1,17) & 0.7460 \\
Obs*R-squared & 0.120385 & Prob. Chi-Square(1) & 0.7286 \\
\hline \hline
\end{tabular}


Test Equation:

Dependent Variable: RESID ${ }^{\wedge} 2$

Method: Least Squares

Date: 06/19/15 Time: 11:51

Sample (adjusted): 19962014

Included observations: 19 after adjustments

\begin{tabular}{lllll}
\hline \hline Variable & Coefficient & Std. Error & t-Statistic & Prob. \\
\hline \hline C & $2.35 \mathrm{E}+09$ & $6.87 \mathrm{E}+08$ & $\begin{array}{l}3.419244 \\
-0.329241\end{array}$ & 0.0033 \\
RESID^2(-1) & -0.079627 & 0.241851 & -7460 \\
\hline \hline R-squared & 0.006336 & Mean dependent var & $2.17 \mathrm{E}+09$ \\
Adjusted R-squared & -0.052115 & S.D. dependent var & $1.87 \mathrm{E}+09$ \\
S.E. of regression & $1.92 \mathrm{E}+09$ & Akaike info criterion & 45.69053 \\
Sum squared resid & $6.28 \mathrm{E}+19$ & Schwarz criterion & 45.78995 \\
Log likelihood & -432.0601 & Hannan-Quinn criter. & 45.70736 \\
F-statistic & 0.108400 & Durbin-Watson stat & 1.982362 \\
Prob(F-statistic) & 0.745995 & & \\
\hline \hline
\end{tabular}

Source: Author's computation, 2016

Prob $=\mathbf{0 . 7 2 8 6}>\mathbf{0 . 0 5}$. So the probability to accept the basic hypothesis is high and we accept it. We have homosedasticity.

\section{The average residue testing}

Will test that the average residue is zero.

\section{Hypothesis:}

$\rightarrow \quad \mathrm{H} 0: \overline{\mathrm{e}}=0$

$\rightarrow \quad$ Ha: $\overline{\mathrm{e}} \neq 0$ (parameters are not good for prediction)

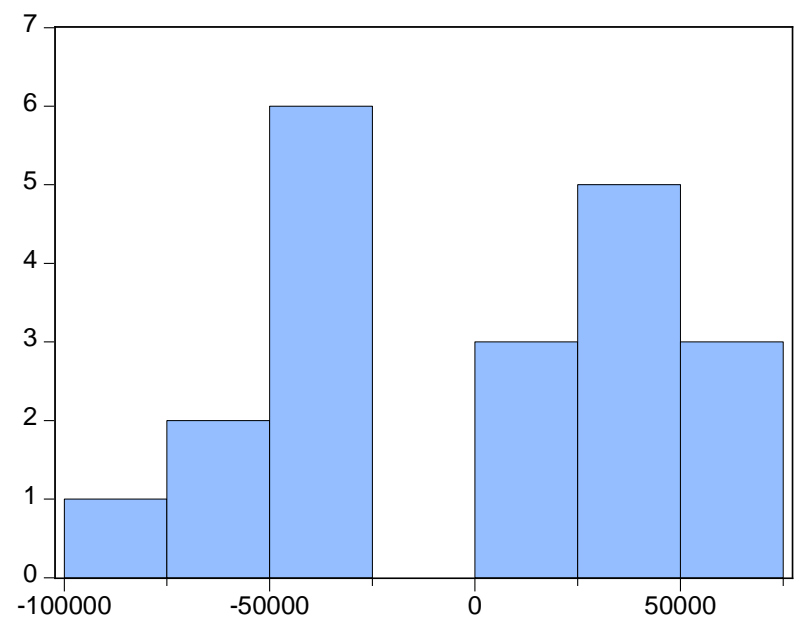

Series: Residuals

Sample 19952014

Observations 20

Mean

Median

Maximum

Minimum

Std. Dev.

Skewness

Kurtosis

Jarque-Bera

Probability
$-2.36 \mathrm{e}-11$ 11605.27

61401.09

$-86431.09$

47427.43

$-0.252713$

1.697868

1.625837

0.443562

Source: Author's computation, 2016 
IēI $/\left[\mathrm{Se} /(\mathrm{n}-1)^{1 / 2}\right]=-2.36 \mathrm{e}^{-16} /\left(47427.43 / 19^{1 / 2}\right)$

Factical value $>1.96$. We accept the alternative hypothesis, the residue does not have the average 0 . This can be observed in the chart.

\section{Testing the normality of the distribution of residue}

a) Jarque Berra test, fully test whether the distribution is normal or not.

Hypothesis:

$\rightarrow \quad \mathrm{H} 0:$ normality

$\rightarrow \quad \mathrm{Ha}:$ lack of normality (parameters are not good for prediction)

Prob. $=0.443562>0.05$, The probability to accept the basic assumption is significant, so we say that we have normal residue.

b. The asymmetry test (Skweness), it test whether the distribution has a normal asymmetry or not.

Skweness follows : $\beta \Xi N(0 ; \sqrt{ }(6 / n))$.

Factical value : Skweness $/ \sqrt{ }(6 / \mathrm{n})$

Hypothesis:

$\rightarrow \quad \mathrm{H} 0$ : normality of asymmetry

$\rightarrow \quad$ Ha : lack of asymmetry normality (parameters are not good for prediction)

Factical value of asymmetry: $-\mathbf{0 . 2 5 2 7} / 0.5477=-0.4613<1.96$

We accept the basic hypothesis with $5 \%$ risk, and have Normality of Asymmetry of the distribution of residue

c. Pressure test (Kurtosis), tests wether the distribution has a normal pressure or not.

Kurtosis follows : $\beta \Xi \mathbf{N}(3 ; \sqrt{ }(24 / \mathrm{n}))$

Factical value: (Kurtosis-3) $/ \sqrt{ }(24 / \mathrm{n})$

Hypothesis:

$\rightarrow \quad \mathrm{H}_{0}:$ normality of pressure

$\rightarrow \quad$ Ha : lack of pressure normality (parameters are not good for prediction)

Factical value of pressure: -1.302132 / 1.0954=- $1.18872<1.96$

We accept the basic hypothesis with $5 \%$ risk, and have Normality of Pressure of the distribution of residue

\section{Testing of autocorrelation}

Test by Durbin Watson test.

Hypothesis:

$\rightarrow \quad$ Ho: lack of autocorrelation

$\rightarrow \quad$ Ha: autocorrelation (parameters are not good for prediction)

$\Rightarrow \quad$ We are at $\mathrm{d} 2<\mathrm{DW}<4-\mathrm{d} 2$

We accept the null hypothesis. We have lack of autocorrelation 


\section{Conclusions}

1) Various researches show that there is a positive correlation between SMEs development and economic growth. SMEs generate jobs, increase national income, contribute to innovation, increase competitiveness, productivity, reduce poverty, increase exports, reduce imports, etc.

2) Through this study we reached the conclusion that large and micro enterprises affect the economic growth of Albania. This result can be explained based on the fact that large enterprises are more competitive than SMEs. They can easily withstand economic crises than SMEs, through the use of economies of scale. Another important argument which support the concluded result, is that large firms are those that create the trend. While micro enterprises follow the trend. This is the argument why micro enterprises impact on the economic increase.

3) The result achieved empirically, was also proved thanks to the various diagnostic tests, which confirmed the accuracy of the model, arguing that the model:

- Has lack of heterosedasticity

- The overall residue equals zero

- The distribution of residue follows a normal distribution

- There is a lack of autocorrelation between residues

\section{References}

Acs, Z.J.,\& Szerb, L (2007). Entrepreneurship, economic growth and public policy. Small Business Economics, 28(2/3), 109-122.

Acs, Z. J., \&Audretsch, B.D.(1987).“Innovation, Market Structure and Firm Size.” Review of Economics and Statistics 69, 567-574

Aris,N.M (2007). SMEs: Building Blocks for Economic Growth. Paper presented in National Statistics Conference 4-5 September 2006. Department of Statistics.

Ayyagari, M \& Beck, Th \&Kunt,A. (2005). "Small and Medium Enterprises across the Globe: A New Database”. World Bank Working Paper WPS2127

Beck, T., Demirgüç-Kunt, A. \&.Levine,R(2005).“SMEs, Growth, and Poverty,” NBER Working Paper 11224.

Beck,Th \& Demirguc-Kunt,A\& Levine,R(2004). SMEs, Growth and Poverty: Cross-Country Evidence.

Bis Working Papers, nr. 475; SMEs, Financial Constrains and Growth, by Ryan Banerjee

Coase, R. H, (1937). "The Nature of the Firm." Economica 4, 386-405.

Davis, S. J., Haltiwanger,J \&Schuh,S. (1993). "Small Business and Job Creation: Dissecting the Myth and Reassessing the Facts." Business Economics 29, 13-21.

Edinburgh Group, Growing the Global Economy through SMEs

Instat, Statistical Register of Companies, (2014-2015). (available at http://www.instat.gov.al)

Katua,N.TH, (2014). The Role of SMEs in Employment Creation and Economic Growth in Selected Countries, 461-472.

Kawai,H \& Urata, Sh (2002). "Entry of Small and Medium Enterprises and Economic Dynamism in Japan." Small Business Economics 18, 41-51.

Little, Ian M.D. (1987). "Small Manufacturing Enterprises in Developing Countries.” World Bank Economic Review 1, 203-235.

OCDE, High - Growth SMEs and Eployment.

OECD (1996), Technology, Productivity and Job Creation, Paris.

OECD, Promoting Entrepreneurship and Innovative SMEs in a Global .

Pagano, P \&Schivardi,F .(2001). "Firm Size Distribution and Growth.” Banca d'Italia Working Paper 394. 